ISSN 1112-9867

\title{
TEACHING AND LEARNING OF PRE-CALCULUS: AN INSIGHTS OF EDUCATORS
}

\author{
A. M. Nasir ${ }^{*}$, N. A. B. Omar, E. S. B. Sarudin, S. Masrom and N. H. Ahmad \\ Faculty of Computer and Mathematical Sciences, UniversitiTeknologi MARA, Tapah, Perak, \\ Malaysia
}

Published online: 10 November 2017

\begin{abstract}
The high-failure of Calculus courses has bring dilemma to the educators worldwide. This study has focus on teaching and learning of Pre-Calculus, a fundamental course for higher level Calculus courses. A well-designed questionnaire was distributed to all respondents to find the difficulties faced by both lecturers and students from the insights of the educators. From the survey, we find that lecturers confronted difficulties in teaching Pre-calculus caused by the lack of basic and visualization skills among students. They find that students' performance are moderate since they tend to memorize, instead of understand the concept. Indeed, most of them agree that the major problem of students is the poor foundation in basic Calculus. Therefore, they have suggested three ideas which are changes of mindset among students, consult lecturers whenever students have problems and remedial class for the weak students.
\end{abstract}

Keywords: pre-calculus; high-failure rate; teaching and learning; lecturers' insights.

Author Correspondence, e-mail: arfah485@perak.uitm.edu.my

doi: http://dx.doi.org/10.4314/jfas.v9i6s.35 


\section{INTRODUCTION}

Many researches have been conducted to study the teaching and learning of Mathematical courses. Researchers have recognized the importance of basic Mathematics knowledge in learning and understanding of new Mathematics knowledge [1]. Relevance to that, they also find the important of Mathematical skills for future career development. According to[2], mathematics is an important subject since it is highly related to both academic and career opportunities. Similarly, in [3]stated that Mathematics is very important to the science and the properties of this course are needed as basic requirement for all sciences. While,in [4]find that Mathematics education is an important skills for employment. Based on the statements, the importance of Mathematics is undeniable. However, it is very disappointed to mention that the performance of undergraduate students on particular subjects of Mathematics are not encouraging anymore. Many students find that Mathematics is just a compulsory subject to graduate and they have a bad attitude towards this course.

Over the time, the concern about Calculus has been discussed in many countries. The high failure rate in every institution and programs has affect the image of education system. As stated by[5], Calculus is one of the high-failure rate courses for engineering students and this matter has affect the program since Calculus commonly a pre-requisite subjects. In MARA University of Technology (UiTM), the concerns regarding poor performance of diploma students in Calculus courses have been highlighted in [6]. The study mentioned that Pre-Calculus, Calculus I and Calculus II are courses that had been identified as critical Calculus courses. Therefore, a lot of researches conducted in UiTM with regard to this issue such as[7-8]. With relevance to the situation, UiTM Perak Branch, Tapah Campus also faced similar situation where the poor performance of students in Calculus courses have create dilemma among the educators. Therefore, this study was conducted to find the lecturers' insights on teaching and learning of one of the important Calculus courses which is Pre-Calculus.

Researchers stated that one of the main reasons of high failure rate is the poor foundation of basic Calculus [7]. Thus, this research focus on Pre-Calculus since this subject contains the fundamentals to the other Calculus courses. By finding the insights of teaching and learning of Pre-Calculus, this research aims to improve the performance of students in Calculus 
courses. The research objectives of this research are to investigate the lecturers' insights on the teaching and learning of Pre-Calculus and to study whether poor foundation in basic calculus is the major reason of students' underachievement in all Mathematical courses. While the research questions are to figure out what are the lecturers' insights on the teaching and learning of Pre-Calculus?, what are the lecturers' insights on the students' Pre-Calculus understanding and students' difficulties in learning Pre-Calculus subjects?, what are the suggestions given by the lecturers to improve students' performance in Pre-Calculus subjects?, what are the lecturers' opinion on students' skill in Calculus courses and the topics that are hard to understand by the students?

Finally, the significance of this study are to provide important information for the administrators of UiTM Perak Branch, Tapah Campus to organize a better plan for various academic programs on Calculus and to give important inputs to the lecturers in improving their teaching for Calculus courses. On the same time, students would use the information to make a change in their learning process of Calculus courses, especially Pre-Calculus. Besides, the researchers could use this study as reference for future improvement in their future research.

\section{LITERATURE REVIEW}

Educators in higher learning institution have raised the issue regarding high-failure rate in Calculus courses for such a long time. They have embarked a lot of studies to improve students' improvement in this subject. However, their attitude towards Mathematical courses has being the main barriers to the performance. According to. [9], students find that they have phobia towards this course and feel that they are not smart enough to solve Mathematics problems. Besides, their past experience during SPM Additional Mathematics has affect their performance at undergraduate level. This statement was supported by[10] that mentioned students who did poorly in their SPM Additional Mathematics usually have poor performance in the first year basic Calculus examinations at university.

In 2005, in [11] has reported a high-failure rate percentage in the Basic Calculus course among engineering students. This poor performance has raised concerns among lecturers and the institution itself. It is because students who failed the Calculus course need to retake the 
subject in order to progress to the higher level of Calculus course since commonly it is a pre-requisite subject. This situation had brought sorrow to the students and institution since it might affect the percentage of graduates on time. In the same situation, in [11] also revealed that they are facing the difficulties in teaching and learning of Calculus courses at University Technology of Malaysia (UTM) [12]. In addition, in[6] also reported average passing rate for Pre-Calculus in below 70\% for diploma students at UiTM Sarawak. Overall, it shows that the problems in teaching and learning of Calculus courses happened in every institution.

From the previous researches, many studies have discuss about the issue of Calculus courses in their institution $[6,11-12]$. Contrast to the other researches, this study focus only on the basic Calculus course, which is Pre-calculus. By doing some improvement on the questionnaire suggested by [6], a questionnaire consists of three sections was designed to find the insights of teaching and learning for Pre-Calculus itself. Some components of the questionnaire was based on the finding in [6] such that designing teaching activities related to real life situations and use of ICT for visualization are suggestions to improve the students' performance. Instead of that, in [13]suggest the necessity of special educational support programs for students who were admitted with low high school performance records. Therefore, one of the components included in the questionnaire is setting up a remedial class for first year studies, which catered for students who are weak in Mathematics. Hence, the questionnaire was well-designed based on the finding in previous researches.

\section{METHODOLOGY}

This study is a survey research conducted to investigate lecturers' insight on the teaching and learning of Pre-Calculus. This study aims to find out the real problems faced by both lecturers and students in the learning process of Pre-Calculus based on their experience. Therefore, a survey has been conducted in UiTM Perak Branch, Tapah Campus to gather a reliable evidence on the teaching and learning of Pre-Calculus respectively.

\subsection{Population}

The respondents of this study consisted of all Mathematics lecturers in UiTM Perak Branch, Tapah Campus. There are 24 lecturers with different level of experiences involved in this 
survey. Some of them never taught Pre-calculus, but they used to teach a higher level Calculus courses. Therefore, they are also qualified to answer this survey since one of our objective is to study whether poor foundation in basic calculus is the major reason of students' underachievement in all Mathematical courses.

\subsection{Instrument}

For the purpose of studying the lecturers' insights on teaching and learning of Pre- Calculus, a questionnaire was design and given to the respective lecturers. The questionnaire was divided into three sections. Section 1 was design to study the lecturers' insight on teaching pre-calculus. Therefore, the lecturers were asked about their difficulty in teaching the courses and listed the topics that they find tough for students to understand. Besides, this section also included the respondents' demographic such as gender, length of teaching Calculus and whether they used to teach Pre-Calculus or not.

Meanwhile, section 2 was designed to study lecturers' insights on students' Pre-calculus learning process. This section is more detailed since lecturers' were asked to rate their students' understanding in this subject and state the difficulties that faced by most of their students. In addition, they also asked to choose a few suggestions to improve students' performance in Pre-Calculus. As for information, the difficulties and suggestions listed in this questionnaire was based on the result of [6].

Finally, section 3 is the section that was created to answer the second objective. It can be answered by any of the respondents whether they used to teach Pre-calculus or not. This section would like to study lecturers' insights on students' skills in learning Mathematical courses. In this section, lecturers were asked about the opinion on a statement regarding major problem that caused students underachievement and they were asked to list out the basic calculus topics that students lacking.

This questionnaire was designed with reference to [6]. Two Mathematics lecturers under study were asked to check and verify the items in the questionnaire in order to meet the objectives of this study. Any correction on grammar and the items in the questionnaire were made before the questionnaire was distributed to the respondents of this study.

\subsection{Data Collection Procedure}

For the purpose of studying the two objectives listed, an online questionnaire was distributed 
to the Mathematics lecturers. This study used Google Forms to create an online questionnaire in order to easily approach the respondents. Indeed, the respondents also find it more convenient since they can take their time to answer the questionnaire. The feedback from the respondents was online generated to the admin account of the Google Forms.

\subsection{Data Analysis Procedure}

Analysis of the questionnaire was online generated through Google Forms. Google forms provide two analyses which are individual respond and the summary of the responds. We have confirmed the content of the result by carried out the individual responds and analyze it using Microsoft Excel.

\section{RESULTS AND DISCUSSION}

The finding was divided into two sections which aims to answer the two research objectives of this study. These sections consist of the lecturers' insights on the teaching and learning of Pre-Calculus and poor foundation in basic calculus is the major reason of students' underachievement in all Mathematical courses.

\subsection{Lecturers' Insights on the Teaching and Learning of Pre-Calculus}

These sections are created to answer the first three research questions listed. Demographically, the respondents who answer the questionnaire are $87.5 \%$ female and the balances are male. In terms of experience, $68.8 \%$ of the respondents have been teaching Calculus in UiTM for more than five years, $25 \%$ of them have experience from one to three years and only $6.2 \%$ have experience less than one year as shown in Fig. 1. Therefore, most of the lecturers are skilled enough in teaching Calculus courses for university students. Moreover, $68.8 \%$ of the respondents have experience in teaching Pre-Calculus. So, the respondents were familiar with the syllabus content and also the students' skills in this course. 


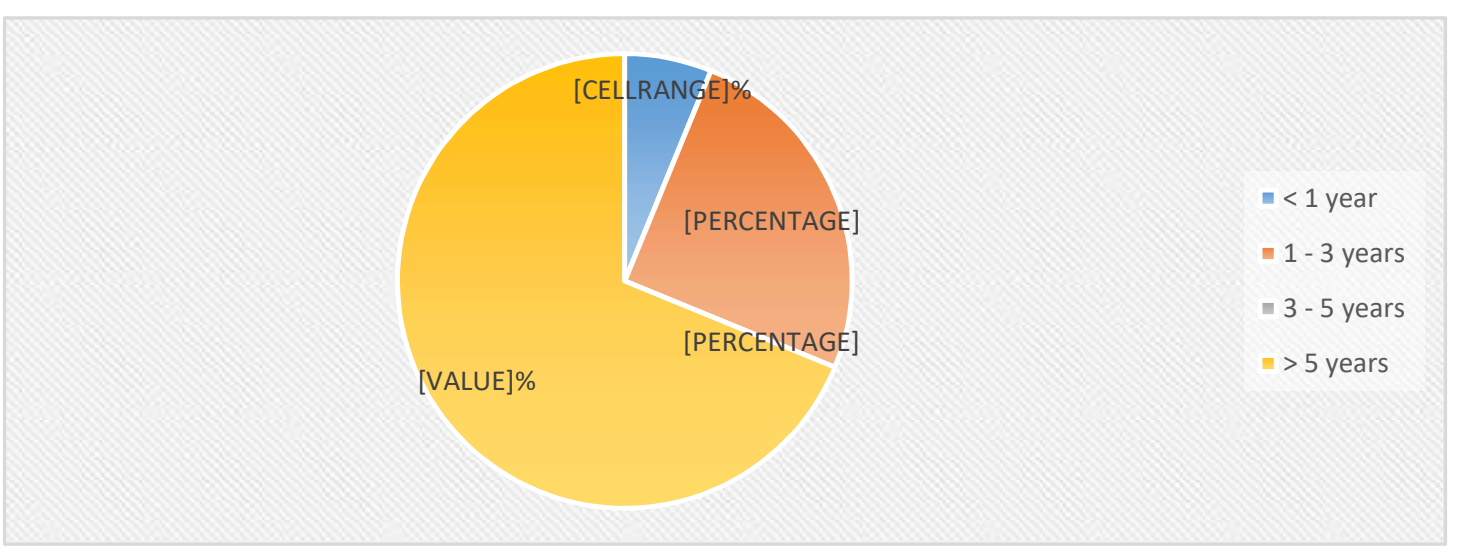

Fig.1. Length of year(s) teaching calculus in UiTM

From the response received, we have found the major difficulties faced by educators during the teaching and learning process of Pre-Calculus as shown in Fig.2. Based on the survey, $77.8 \%$ educators find that students are generally very weak in basic mathematics skills required of this course. It means that students do not have strong basic as preparation for Pre-Calculus. The basic of Mathematics that was taught in school are not fully understood by the students and led to the weak performance during university level. Besides that, $66.7 \%$ of them state that students cannot visualize the various Calculus concepts. In this case, students did not have enough creativity and imagination skills. Therefore, they are having trouble in digesting the concepts taught. Both of those major problems were agreed by [6] that find the lecturers have difficulties to explain the Calculus concept caused by the lacking in basic Calculus and visualization skills among students. Next, another difficulty faced by the educators is the lack of interest during the lesson due to the past experience with the percentage of $55.6 \%$. This finding is supported by [14] that state the main reason of low performance in Mathematics is due to the students' attitude towards the subject. Students regarded this course as a boring subject, difficult and no relevance to their future. For this situation, students who are not from Mathematics program find that Pre-Calculus is not important their future. Because of that, they indirectly had put some resistance in learning this subject. According to $[9,15]$, they also found that the difficulty, dislike, lack of confidence, bore and lack of relevance has reduced the participation of Mathematics in UK. In addition, lecturers also find that time constraint is one of the difficulties that they need to deal with. They find that they have limited time to cover the syllabus of Pre-Calculus and have no time 
revising the basic Calculus. Commonly, any course has its own syllabus content and the scheme of work was well-planned to fit the 14 weeks learning process. However, the unprepared students (etc. poor basic of Calculus) havemade it tougher for lecturers to follow the original scheme of work. Thus, lecturers find that it is inconvenience for them to finish everything in 14 weeks. These results are shown in Fig. 2.

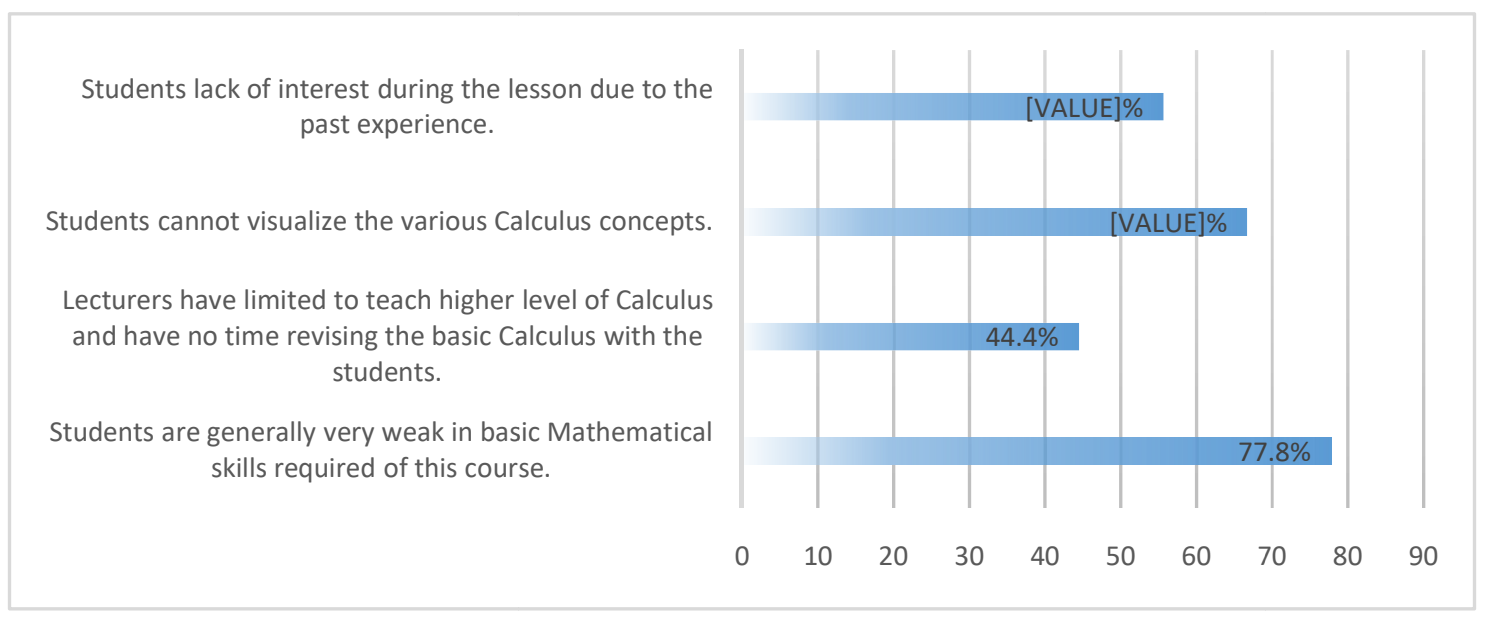

Fig.2. Difficulties from lecturers' insights

Instead of that, the lecturers also have choose three main sub-topics that is tough for students which are Logarithmic and Exponential Functions (81.8\%), Trigonometric Equations (63.6\%) and Trigonometric Identities and Domain and Range of a Function that shared the same percentage (54.5\%). Besides that, the other topic that has been highlighted by the respondents is transformation of graph, plane analytic geometry, system of inequalities and simultaneous linear equations. The result in Fig. 3 is actually beneficial to both lecturers and students. It is because they can make their own planning before the semester start. For instance, lecturers can spend more time and discuss more exercise on the critical topics. They can also allocate the right amount of time that he/she should spend on each topics based on their difficulties. While, students can make a better study plan to ensure that they did not miss any class related to the tough subjects. Besides, they can also study the basics of the tough topics as preparation for a higher level Mathematics for the course. Thus, these result answer the first research question which is the lecturers' insights on teaching and learning of Pre-Calculus. 


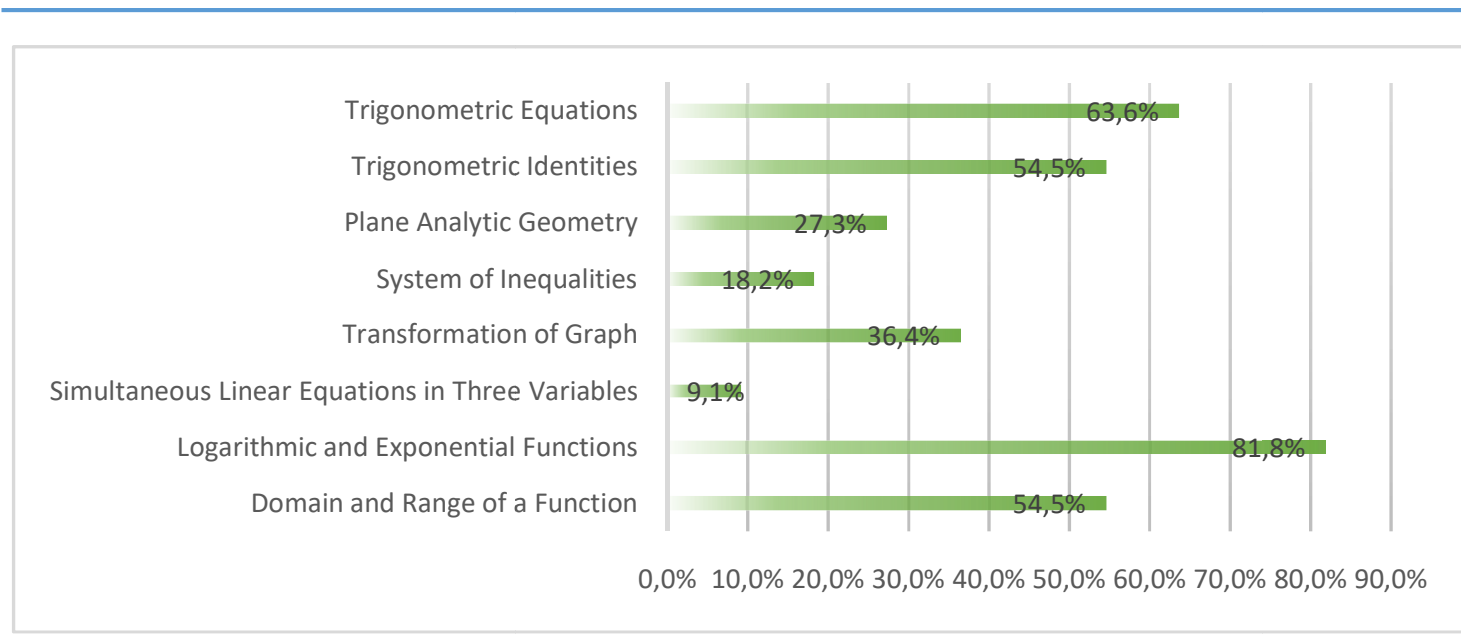

Fig.3. List of topics that is tough for students to understand

Next, we are going to discuss the students' understanding and difficulties from the lecturers' insights. To measure the students' understanding on Pre-Calculus, we have used the linear scale from 1 (bad) to 5 (excellent). The result from the Fig. 4 shown that $60 \%$ of respondents choose scale $3,30 \%$ choose scale 4 and $10 \%$ choose scale 2 . Based on the percentage, we can say that most lecturers find that their students have moderate understanding on Pre-Calculus and only $30 \%$ of the students that have a good performance in this subject. In line with that, $72.7 \%$ lecturers stated that their students hardly understand the concept and tend to memorize it. This issue has been raised by many educators before, which is students prefer to take short cut in learning process. They prefer to memorize the concept instead of trying to understand it. From their perspective, memorizing will at least help them to pass the exam. However, when the questions are a little bit tricky, they could not answer it because their lack of understanding. Besides that, other difficulties that commonly face by students are the formula. 63.6\% lecturers find that students can memorize the formula but unable to apply it for the particular problem. It is undeniable that formula is very important in Calculus courses and Pre-Calculus it consists of a few critical topics that require students to memorize the formula. As everyone knows, formula was created to make it easier for the students to solve the problems. However, memorizing the formula without understand the used of it is a wrong thing to do. Indeed, students should know the function of the formula provided and when to use it. Contrast to that, students sometimes has problem to identify the correct method for certain problems $(63.6 \%)$. For this problem, it is actually the combination of the first two problems. It is because students are not bothering the find out the function and the difference 
of each of the methods they have learned. Therefore, they tend to be confused and make a mistake in solving the Pre-Calculus problems. Next, another major problem faced by students is they always think that Pre-Calculus is very difficult subject before they even trying to answer the question (54.5\%). The negative mindset also plays an important role in this case. When people have put that kind of though in their mind, they tend to stop trying and give up in understanding the lesson. Students who have bad experience during school are most probably expose to this problem and perform badly in higher education. Hence, those responses received in Fig. 5 have given an overview of students' understanding and difficulties in learning Pre-Calculus.

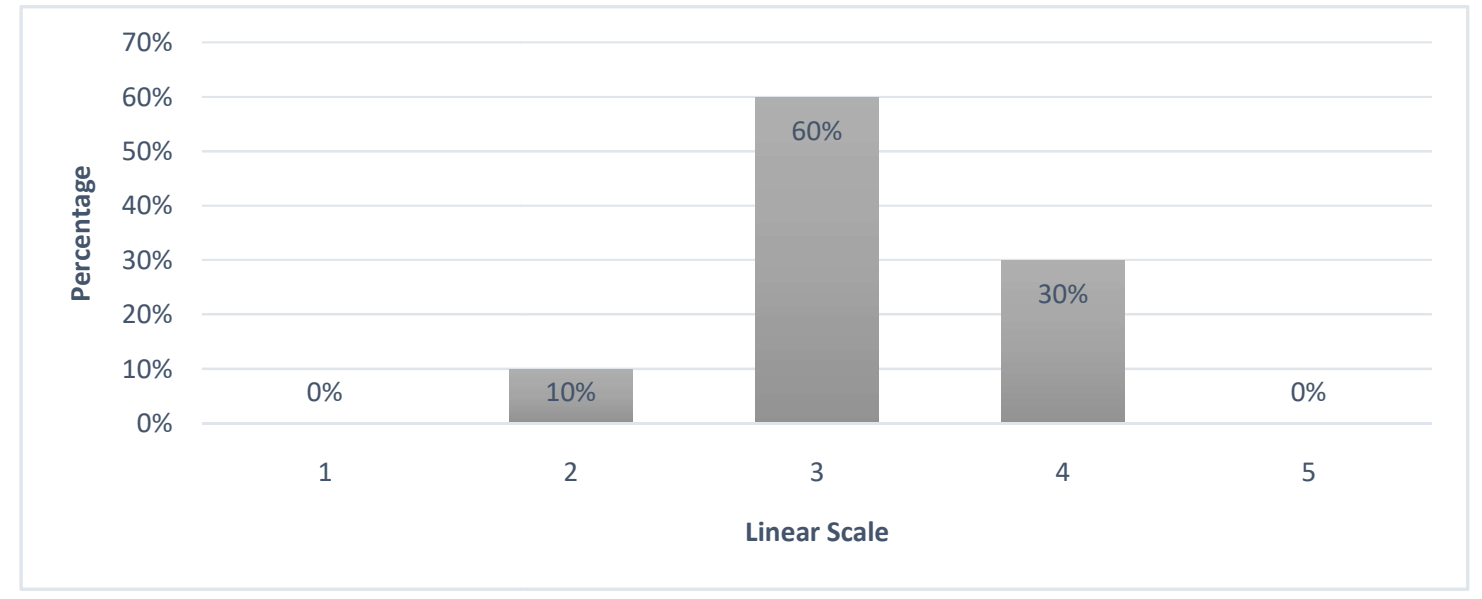

Fig.4. Linear scale of students' level of understanding

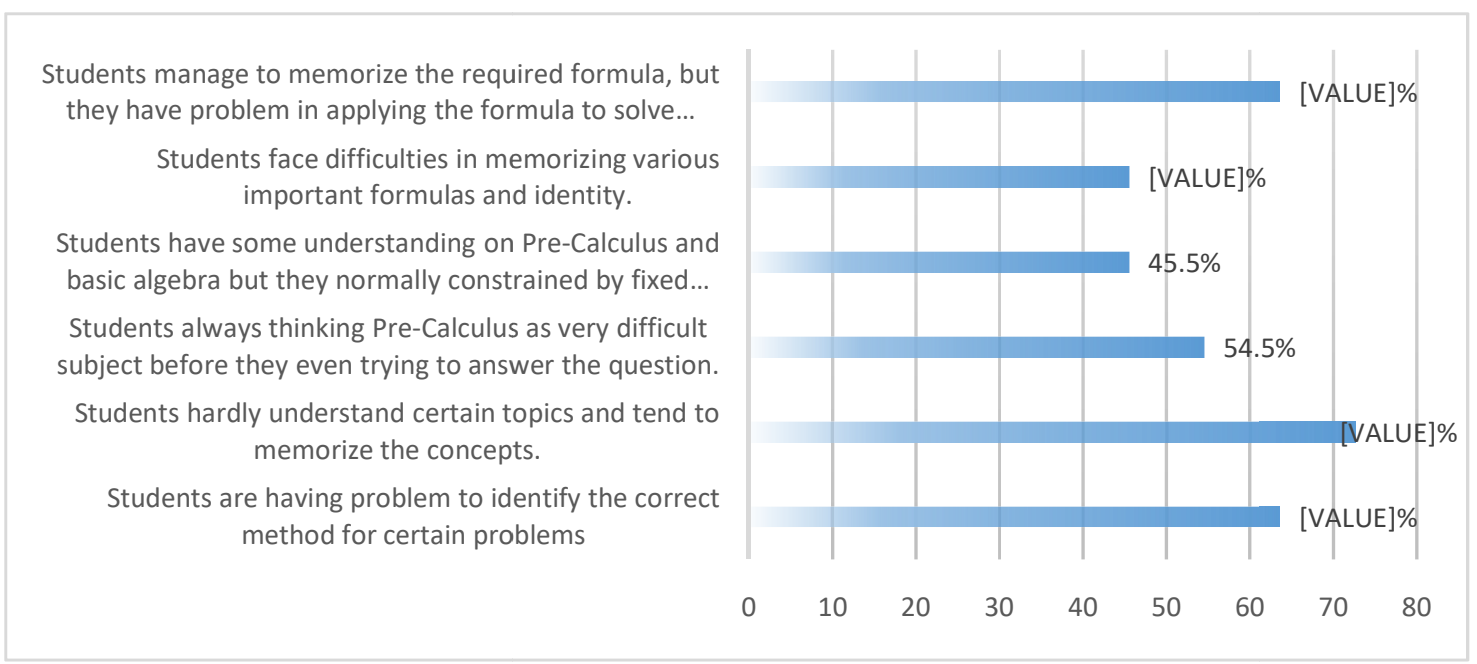

Fig.5. Difficulties faced by students in learning pre-calculus

Afterward, the respondents were asked about the suggestion to improve the students' performance in Pre-Calculus. We do believe that many alternatives have been conducted to 
improve the students' performance in Calculus. However, these studies try to focus only on Pre-Calculus, a subject that served as preparatory fundamentals to the other Calculus courses. From the survey, we have listed nine suggestions that have been finding by[6]. As the result shown in Fig. 6, we find that 45.5\% lecturers want the students to change their mindset on this course and cooperate well in attending lectures and tutorial class. This statement was discussed in $[14,9]$ that mentioned about students' bad attitude to Calculus has affected their performance. Besides, their cooperation in attending the class also will affect their performance. It is because learning through an experience educator is better compared to study alone or with friends. Being guided by the lecturers will help students to understand the lesson well. Next, another two suggestions choose by the lecturers are students should consult lecturers whenever they face problems and setting up a remedial class for first year studies which catered for students who are weak in Mathematics. Both of the suggestions share the same percentages which are $18.2 \%$. Consultation and remedial class are two important alternatives in learning process and agreed by[16]. Nowadays, students refused to consult lecturers whenever they have problem with the lesson. They preferred to discuss it only with their friends and this is not healthy. Students supposedly asked the lecturers during the class and make use of the face-to-face time well. Besides that, another two suggestions choose by the respondents are the usage of ICT to visualize the various Pre-Calculus concepts and designing teaching activities related to real life situations and formulate Pre-Calculus problems in real life contexts. ICT has been implemented in teaching and learning process since the young generation has good preference on this method. They find it convenience to use ICT in their lesson. Indeed, they tend to attend class that has certain activities related to the lesson. Finally, this result shown that the changes of mindset and attitude toward this course are very important to improve the students' performance. 


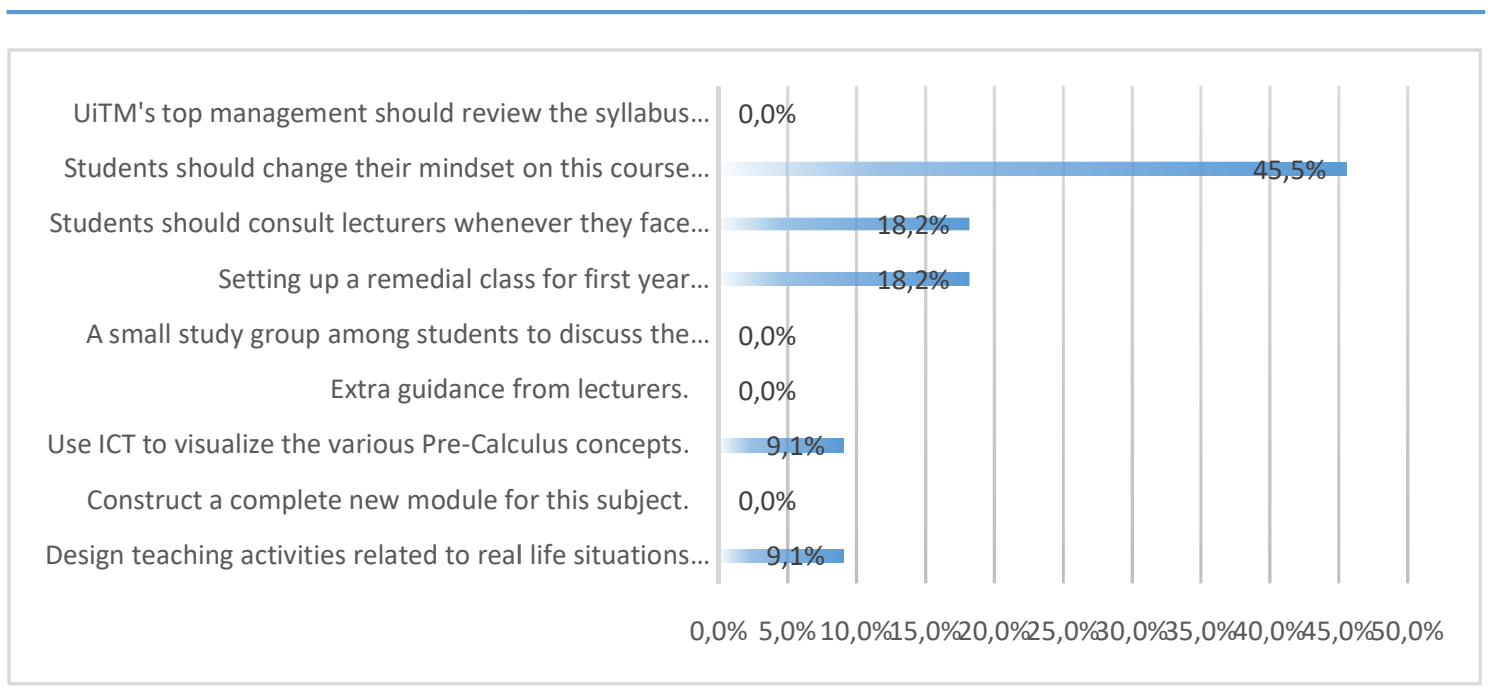

Fig.6. Suggestions to improve students' performance in pre-calculus

\subsection{Poor Foundation in Basic Calculus among Students}

According to [12], students who did not have a solid foundation of basic Calculus tend to have a problem in learning the new material in Calculus courses at undergraduate studies. They be likely to fear to try and lose confidence in solving Calculus problems. Therefore, this study has included two questions in section 3 to get the real picture of the students' skills in Calculus. This section was answered by all Mathematics lecturers at UiTM Perak Branch, Tapah Campus. So, these feedbacks represent the lecturers' insights on all students (different programs) who took Calculus courses.

Based on the feedback received as shown in Fig. 7, 93.3\% respondents agree with the statement that the major problem that caused students' underachievement in Mathematics was students' poor foundation in basic calculus. Indeed, when they were asked about the topics that students are lacking, the responds are really surprising. About $86.7 \%$ lecturers find that basic of integration is the major topics that need to be improved by the students. Followed by basic of differentiation and logarithmic and exponential functions that shared similar percentage which is $73.3 \%$. Besides, $46.7 \%$ lecturers find that their diploma students still lacking in basic of algebra and followed by indices $40 \%$. In addition, $26.7 \%$ lecturers discover that some of their undergraduate students are still having problems in basic operation (BODMAS). 


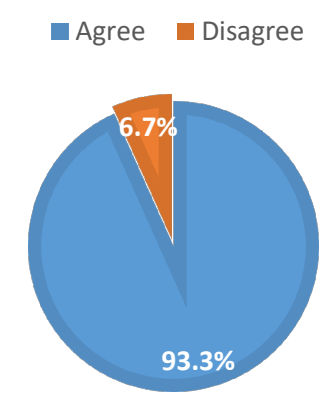

Fig.7. Percentage of respondents who find poor foundation in basic calculus is the major problem

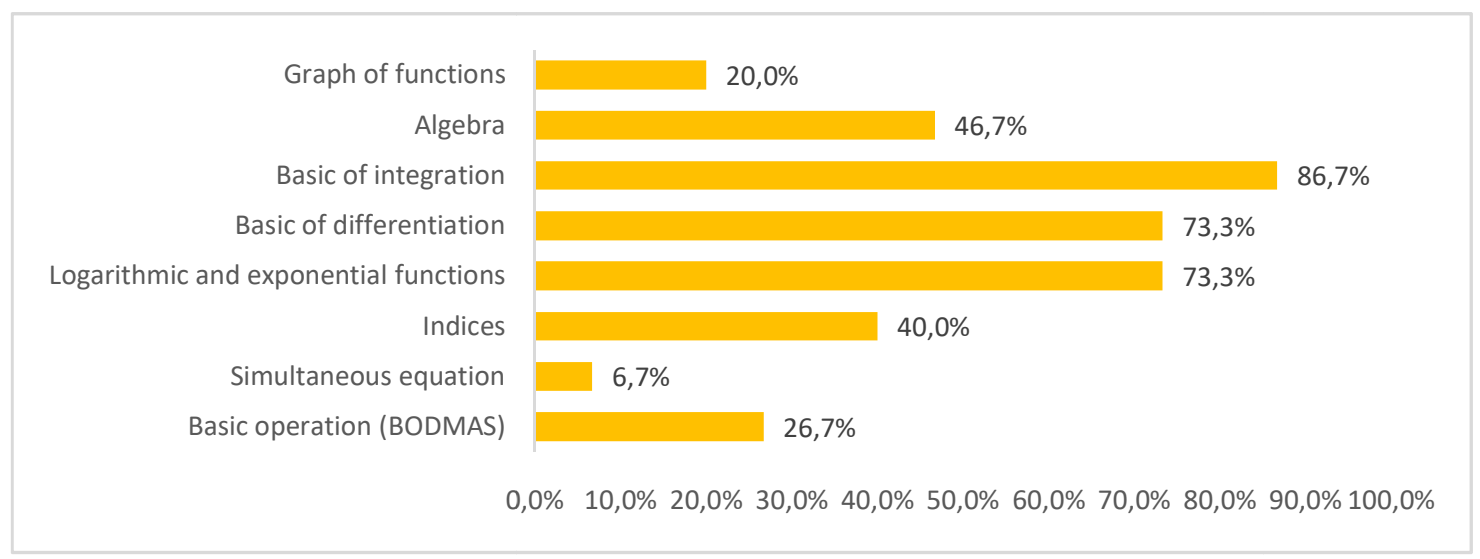

Fig.8. Topics of pre-calculus that require improvement from students

By referring to the results in Fig. 8, we find that all the topics that students were lacking has been taught in Additional Mathematics SPM. This finding indirectly shows the real skills of students during secondary school. Besides, this result was supported by [8] that find SPM Additional Mathematics is a good predictor to the bad performance of underachieved Mathematics courses. It is because SPM Additional Mathematics content is actually an introduction to the knowledge of Pre-Calculus, which served as preparatory fundamentals to the other Calculus courses offered in UiTM, such as Calculus I, Calculus II, Discrete Mathematics and others. Thus, we find that poor foundation in basic calculus is the major reason of students' underachievement in all Mathematical courses and this problem has started during their first introduction to the Calculus which is in secondary school.

\section{CONCLUSIONS AND RECOMMENDATIONS}

This paper has conducted to investigate the lecturers' insights in teaching and learning of 
Pre-Calculus. By listing two main objectives and four research questions, we aims to help improve the students' performance in Calculus courses. Pre-Calculus has served as the preparatory fundamentals to the other Calculus courses. According to [11], the basic in Calculus should be improve to ensure that students can perform well in the future. Therefore, the skills in Pre-Calculus must be given a lot of attention since it will determine the students' performance in the higher-level of Calculus courses.

This study has been conducted through an online survey to avoid any inconvenience among respondents. All respondents were given enough time to answer the questionnaire. Based on the result, we find that the respondents are mostly experience lecturers since they have been teaching at UiTM for more than 5 years and most of them also have taught Pre-Calculus during their service. Through the survey, we found that lecturers' has faced a lot of difficulties in teaching Pre-Calculus. The difficulties that they have are students unable to follow the lesson well since they are very weak in the basic mathematics skills and unable to visualize the concept of Calculus. In addition, the past experience has led to the lack of interest during the teaching and learning process. Generally, they have highlighted that Logarithmic and Exponential Functions, Trigonometric Equations, and Domain and Range of a Function are topics that should be focused more since it is tough for students.

Besides that, the respondents find that the students are in moderate performance in average and only $30 \%$ who are good. The lecturers find that students tend to memorize the concept instead of understand it. Therefore, they usually face problems such as cannot apply the formula and unable to determine correct method for certain problem. In order to solve this problem, the respondents wished that the students can change their mindset on this course and cooperate well in lectures and tutorial class. Indeed, they hope that students could consult them whenever they face problems. Finally, the last suggestion is setting up a remedial class for first year studies which catered for students who are weak in Mathematics. Next, the second objective on regards of poor foundation of basic Calculus, we find that $93.3 \%$ respondents agree with the statement. Most of the respondents underlined that students are weak in topics that has been taught in SPM Additional Mathematics such that basic of integration, differentiation and logarithmic and exponential functions.

As for recommendation, future research can conduct a case study to implement the 
suggestions from the respondents. Through future research, we can determine whether the suggestions from this study are efficient or not. Therefore, we will be able to show the students' improvement in Calculus courses.

\section{ACKNOWLEDGEMENTS}

We would like to thank UniversitiTeknologiMARA for the financial support under grant scheme 600-IRMI/DANA 5/3/ARAS (0170/2016).

\section{REFERENCES}

[1] Hailikari T, Nevgi A, Lindblom-Ylänne S. Exploring alternative ways of assessing prior knowledge, its components and their relation to student achievement: A mathematics based case study. Studies in Educational Evaluation, 2007, 33(3-4):320-337

[2] Akinsola M K, Tella A. Effectiveness of individualistic and cooperative teaching strategies in learning geometry and problem solving in Mathematics among junior secondary schools in Nigeria. Personality Study and Group Behaviuor, 2003, 23:95-105

[3] Uche N V A, Kamoru O U.Training of undergraduate teachers in Nigerian universities: Focus on problems of effective integration and attitude of students to computers in mathematics instruction. 2002, http://www.math.uocgr/ ictm2/ Proceeding/gap119pdf

[4] Ketterlin-Geller L R, Chard D J, Fien H. Making connections in mathematics conceptual mathematics intervention for low-performing students.Remedial and Special Education, 2008, 29(1):33-45

[5] Suresh R. Persistence and attrition in engineering: Understanding the nature of students' experience with barrier courses. PhDthesis, New York: University of New York, 2003

[6] Tang H E, Voon LL, Julaihi N H. The impact of 'high-failure rate' Mathematics courses on UiTM Sarawak full-time diploma students' academic performance.Selangor: Research Management Institute, UniversitiTeknologi MARA, 2008

[7] Eng T H, Li V L, Julaihi N H. Lecturers' perceptions, students' problems and solutions for handling high-failure rate mathematics courses.Procedia-Social and Behavioral Sciences, 2013, 90:853-861

[8] Eng T H, Li V L, Julaihi N H. The relationships between students' underachievement in 
mathematics courses and influencing factors.Procedia-Social and Behavioral Sciences, 2010, $8: 134-141$

[9] Brown M, Brown P, Bibby T. I would rather die: Reasons given by 16-year-olds for not continuing their study of mathematics. Research in Mathematics Education, 2008,10(1):3-18

[10] Yudariah M Y, Roselainy A R. An assessment of the modular approach in teaching and learning first year calculus at UTM. In Conference on Science and Technology Education, 1997, pp. $15-16$

[11] Gynnild V, Tyssedal J, Lorentzen L. Approaches to study and the quality of learning. Some empirical evidence from engineering education.International Journal ofScience and Mathematics Education, 2005, 3(4):587-607

[12] Yusof Y M, Rahman R A. Mathematics education at UniversitiTeknologi Malaysia (UTM): Learning from experience. JurnalTeknologi, 2001, 34:9-24

[13] Islam M M, Al-Ghassani A. Predicting college math success: Do high school performance and gender matter? Evidence from Sultan Qaboos University in Oman. International Journal of Higher Education, 2015, 4(2):67-80

[14]SuanJ S. Factors affecting underachievement in mathematics. In Global Summit on Education, 2014, pp. 13-20

[15] Tachie S A, Chireshe R. high failure rate in mathematics examinations in rural seniorsecondary schools in Mthatha District, Eastern Cape:Learners' attributions.Studies of Tribes and Tribals, 2013, 11(1):67-73

[16] Ennis T, Sullivan J, Louie B, Knight D. Unlocking the gate to calculus success: Pre-calculus for engineers-an assertive approach to readying underprepared students. In 120th ASEE Annual Conference and Exposition, American Society for Engineering Education, 2013, pp. $1-23$

\section{How to cite this article:}

Nasir A M, Omar N A B, Sarudin E S B, Masrom S, Ahmad N H. Teaching and learning of pre-calculus: an insights of educators. J. Fundam. Appl. Sci., 2017, 9(6S), 452-467. 